\title{
Effect of pre-incubation and incubation conditions on hatchability and chick quality of Kuroiler chickens
}

\author{
M. Mwesigwa, J. Semakula, P. Lusembo, J. Ssenyonjo, R. Isabirye, R. Lumu and T. Namirimu \\ Mukono Zonal Agricultural Research and Development Institute (MUZARDI), \\ P. O. Box 164, Mukono, Uganda
}

Author for correspondence: Bowa73@gmail.com

\begin{abstract}
A study was conducted to review the effects of pre-incubation and incubation conditions on hatchability and chick quality of Kuroiler chickens. The most important incubation factors that affect hatch time, hatchability and hatch window (temperature, humidity, turning, and ventilation) were reviewed. There was a significant influence $(\mathrm{P}<\mathbf{0 . 0 5})$ of breeder age on hatchability. Also, there was significance $(P<0.05)$ of breeder age on texture of the egg shell; while there was no significance $(P>0.05)$ between size of egg and hatch window. The performance of Kurolilers at the end of the rearing period depended, in part, on the quality of day-old chicks at placement. The quality of day-old chicks was highly affected by the incubation conditions, hatch time (which determines the time spent in the hatchery under high temperature and humidity), and handling of chicks after hatch.
\end{abstract}

Key words: Egg shell, hatch handling, hatch time, hatch window

\section{Introduction}

The Kuroiler is a hybrid of chicken developed in India. Kuroilers are derived from crossing either coloured broiler males with Rhode Island Red females, or White Leghorn males crossed with female Rhode Island Reds (Victoria, 2012).

Kuroilers, a dual-purpose breed producing meat and eggs, can live on a kitchen diet and agricultural waste, and produce around 150 eggs per year, compared with native Indian hens that lay only 40 per year. The meat yield per bird of Kuroilers is also greater. Males weigh approximately $3.5 \mathrm{~kg}(7.7 \mathrm{lb})$ and females about $2.5 \mathrm{~kg}(5.5 \mathrm{lb})$, whereas the native male bird weighs $1 \mathrm{~kg}(2.2 \mathrm{lb})$ and females $0.9 \mathrm{~kg}$ (2.0 lb) Jagdev (2011). Due to its unique genetic features, the Kuroiler is resistant to diseases. The Kuroiler chick is a potential bio-converter of no cost agricultural, household and natural waste abundant in villages, into human protein 
food and substantial incomes for rural In addition, poor performance can be households Jagdev (2011). exacerbated by the early post-hatch

In modern hatcheries, with a fixed management schedule, the end of the Hatch Window (HW) is defined by 'takeoff', i.e the time when most chicks have hatched and are removed from the incubator (The Poultry Site, 2008). The 'hatch window' is an investigation to check the number of chicks hatched after the eggs have been transferred from the setter to the hatcher. If the eggs are hatching too early, the chicks become susceptible to problems such as dehydration. Dehydration to chicks this early could lead to increased 7- and 14day mortality and/or poor performance (The Poultry Site, 2008). If the chicks are hatched too late, the result could be poor hatchability, chick quality problems, and live embryo unhatched eggs (The Poultry Site, 2008).

Hatcheries managers have a common interest in improving chick quality, because their profits are often based on the number of viable chicks after the first week of rearing. Meat chicken chicks hatch after $461-510 \mathrm{hr}$ of incubation (Almeida et al., 2008; Tong et al., 2011). A large HW has been reported to be associated with a high heterogeneity among the batch after placement on rearing farms. According to Careghi et al. (2005), the first chicks hatched 30 hours before take-off, can lose up to $10 \%$ of their body weight; while the last chicks, hatched only 2 hours before take-off, can lose only 1 to $3 \%$ of their body weight. Therefore, a larger HW may result in poor welfare and performance, because early hatched chicks spend up to $50 \mathrm{~h}$ in sub-optimal conditions (air temperature of approximately $37^{\circ} \mathrm{C}, \mathrm{RH}$ $80 \%$ and approx. $1 \%$ of $\mathrm{CO}_{2}$ ) and have a delayed access to feed and water. handling of chicks: sorting, sexing, vaccination, transportation and placement conditions. In commercial hatcheries, sorting, sexing, vaccination do not normally exceed 2 to $4 \mathrm{hr}$. The objective of this study was to review the important factors affecting the hatch window (HW); and establish post-hatch handling and placement factors that impact on performance and health during rearing period.

\section{Materials and methods}

The experiment involved use of three incubators in the same hatchery, each with capacity of 450 eggs. One of the incubators was used as the control. The experiment was carried out from October 2012 to May 2014. Kuroiler chickens were randomly chosen for this research. The day-old chicks fed on chick mash from conventional commercial feeds.

Four batches of day-old Kuroiler chicks (250 in each batch) were raised from brooder through laying period, hatching and off-spring chicks raised. The chicks were also raised through laying, incubation and after-hatch rearing. Two incubators were used in this study, one was used as the control, and the other had conditions including frequency of turning eggs, relative humidity by putting varying amounts of water in the hatch tray.

After brooder, the chickens were separated in a ratio of $1: 8$, male to female, respectively. These sequential events were done for three successive generations; while changing hatchery conditions (that is to say temperature, humidity, turning eggs). Data were recorded on hatchability, hatch window 
(HW), fertility, and survival post-hatch and six weeks into rearing period. The chicken were reared under a deep-litter system, and fed on a conventional commercial feed ration. Data were analysed using Chi-test, descriptive statistics and Statistical Package for Social Science (SPSS).

\section{Results and discussion}

\section{Effect of pre-incubation conditions}

Chick quality and Hatch Window (HW) were not only related to incubation conditions, but also to the quality of incubated eggs (Tables 3, 4 and 5).

The quality of the incubated eggs (fertility, shell thickness and porosity), as well as the duration of incubation were highly affected by the state and age of breeder. In the egg shell gland, calcium carbonate crystals are deposited at a constant rate of about $0.33 \mathrm{~g}$ per hour (The
Poultry Site, 2014). To facilitate smooth, regular shell formation, the egg rotates in the shell gland. Any disturbance of this rotation, for example when the female encounters an aggressive male during mating, produces abnormally formed shell. The shape and texture of the shells is, therefore, a good reflection of the health and well-being of the breeder flock. This understanding is valuable to hatchery managers, not only to help evaluate the quality of the eggs delivered to the hatchery, but also to have valid input into discussions with breeder farm managers about ways in which to improve hatching egg quality. There was a significance influence $(\mathrm{P}<0.05)$ of flock age on egg (shell) quality. Older flocks laid larger eggs with thinner shells (Table 1) and the number of misshapen shells increased.

Poor hatching egg shell quality often resulted in increased weight loss and decreased hatchabilities, with increased

Table 1. Relationship between age of flock, texture and shape of the eggs laid in two chicken generations

\begin{tabular}{|c|c|c|c|c|c|c|}
\hline \multirow[t]{2}{*}{ Age (months) } & \multicolumn{2}{|c|}{ Shape $(\mathrm{N}=400)$} & \multicolumn{2}{|c|}{ Texture $(\mathrm{N}=400)$} & \multicolumn{2}{|c|}{ Size $(N=400)$} \\
\hline & $\begin{array}{l}\text { No. of } \\
\text { eggs oval }\end{array}$ & $\begin{array}{l}\text { No. of } \\
\text { eggs round }\end{array}$ & $\begin{array}{l}\text { No. of } \\
\text { eggs thick }\end{array}$ & $\begin{array}{l}\text { No. of } \\
\text { eggs thin }\end{array}$ & $\begin{array}{l}\text { No. of } \\
\text { eggs big } \\
(>60 \mathrm{~g})\end{array}$ & $\begin{array}{l}\text { No. of } \\
\text { eggs small } \\
(<60 \mathrm{~g})\end{array}$ \\
\hline $8-12$ & 190 & 210 & 320 & 80 & 61 & 339 \\
\hline $15-20$ & 192 & 208 & 202 & 198 & 320 & 80 \\
\hline
\end{tabular}

Table 2. Comparison of hatchability with size of the egg in two generations of Kuroiler chicken

\begin{tabular}{lccr}
\hline Size of the egg $(\mathrm{g})$ & \% Fertility & Hatchability $(\%)$ & Dead in shell \\
\hline$>100$ & $74(\mathrm{~N}=180)$ & 71 & $38(\mathrm{~N}=132)$ \\
$50-60$ & $98(\mathrm{~N}=250)$ & 97.9 & $5(\mathrm{~N}=245)$ \\
$<50$ & $88(\mathrm{~N}=130)$ & 84.5 & $15(\mathrm{~N}=114)$ \\
\hline
\end{tabular}


Table 3. Relationship between age of breeder, size of egg and Hatch Window for three generations

\begin{tabular}{lrrr}
\hline Age of breeder (months) & \multicolumn{3}{c}{ Size of egg $(\mathrm{g})$} \\
\cline { 2 - 4 } & Small $(<50 \mathrm{~g})$ & Medium $(50-60 \mathrm{~g})$ & Large $(>100 \mathrm{~g})$ \\
\hline $8-12$ & $168(\mathrm{~N}=180)$ & $12(\mathrm{~N}=180)$ & - \\
$15-20$ & - & $168(\mathrm{~N}=170)$ & $02(\mathrm{~N}=170)$ \\
Hatch time (hrs) & 485 & 488 & 492 \\
\hline
\end{tabular}

Table 4. Rise in incubation time per day of pre-incubation storage for three generations of incubating Kuroliler eggs in a study done in Uganda

\begin{tabular}{llcll}
\hline $\begin{array}{l}\text { Storage length } \\
\text { (days) }\end{array}$ & $\begin{array}{c}\text { Storage } \\
\text { temperature }\left({ }^{\circ} \mathrm{C}\right)\end{array}$ & Turning & $\begin{array}{c}\text { Increase } \\
\text { of HT hday }{ }^{-1} \\
\text { of storage }\end{array}$ & Reference \\
\hline 1 to 12 & 7.2 to 12.8 & Yes & 1.28 & (Bohren et al., 1961) \\
1 to 14 & 12.8 to 15.6 & Yes & 0.70 & (Crittenden and Bohren, 1961) \\
1 to 8 & 15 & No & 0.70 & (Kirk et al., 1980) \\
3 to 18 & 15 & - & 1.00 & (Tona et al., 2003) \\
\hline
\end{tabular}

risk of cracks during handling leading to dehydration and contamination (Table 2). This agrees with the findings of several researchers (Wilson, 1991; Kumpula and Fasenko, 2005; Wolanski et al., 2007; Almeida et al, 2008). Egg weight increased with breeder age (55 g at 27 weeks compared with $70 \mathrm{~g}$ at 60 weeks (Table 2). A similar observation was made by Tona et al. (2001). Fertility decreased with breeder age, possibly due to the lower efficiency of sperm storage tubes in older hens as reported by Gumulka and Kapkowska (2005). There was significant influence $(\mathrm{P}<0.05)$ of age of breeder on hatchability. Hatchability increased from $88 \%$ for young breeders ( 27 weeks) to a maximum of $96 \%$ at 40 to 42 weeks of age, before dropping to $73 \%$ for older breeders (59 to 61 weeks (Tona et al., 2001; Abiola et al., 2008). The lower hatchability of eggs laid by older breeders was, in part, due to increased total embryo mortality. The findings were in agreement with those of Tona et al., 2001; Vieira et al., 2005; Almeida et al., 2006.

Maximum hatchability (approximately $96 \%$ ), (Table 2), was obtained with medium-sized eggs (50 to $60 \mathrm{~g}$ ) as reported by Wilson, 1991 and Abiola et al., 2008. Hatchability decreased in heavier eggs, for example declined by $5.9 \%$ for eggs weighing 60 to $65 \mathrm{~g}$; and by $13.5 \%$ for eggs weighing more than $70 \mathrm{~g}$ (Kirk et al., 1980). It is not clear whether this reduced hatchability of larger eggs was the result of an increase in the early mortality (Hagger et al., 1986; Rosa et al., 2002; Abiola et al., 2008), or of an increase in both early and late mortality (Elibol and Brake, 2008b) of the embryos.

The number and size of shell pores and shell thickness are factors that influence the ability to exchange gases' fluids and 
Pre-incubation and incubation on hatchability and quality of Kuroiler chickens

heat with the micro-environment around the eggs (Hulet et al., 2007). With the same eggshell porosity, large eggs produce heavier embryos (Burton and Tullet, 1985); and as a consequence have greater difficulty in losing metabolic heat produced by the embryo. Therefore, large eggs hatch better when the incubation temperature is reduced from 37.5 to 36.5 during the second half of incubation (Frech, 1997).

Raju et al. (1997) reported a positive correlation between egg weight and body weight of the resulting broilers at all ages. Breeder age affects egg weight and, therefore, influences chick weight (Tanure et al., 2009). Chicks from larger eggs were significantly heavier at market age; but this effect could not be differentiated from breeder age (Hulet et al., 2007). According to Wilson (1991), chick weight represents 62 to $76 \%$ of the initial egg weight. He concluded that a $1 \mathrm{~g}$ change (positive or negative) in egg weight resulted in a corresponding change of $2 \mathrm{~g}$ to $13 \mathrm{~g}$ in broiler weight at six to eight weeks of age. This effect was more important $(8.2 \mathrm{~g})$ with eggs from young breeders ( 29 weeks old), than with those from older breeders (2.1 g to $2.6 \mathrm{~g}$ at 58 weeks old).

The weight and size of the hatching eggs has been reported to influence the development of chicken intestines in the post-hatch period, regardless of hen age (Vieira and Moran, 1999). Other researchers revealed that chicks hatched from medium-sized eggs (61 to $70 \mathrm{~g}$ ) had a significantly higher intestinal weight, as compared with small-sized (50 to $60 \mathrm{~g}$ ) eggs (Shivazad et al., 2007). Wilson (1991) clearly showed that the incubation time increases with egg weight. The average hatch time (HT) was $488 \mathrm{hr}$ for eggs $52 \mathrm{~g}$, and increased to $494 \mathrm{hr}$ for eggs 
of $72 \mathrm{~g}$ (Burton and Tullett, 1985). Large eggs were not only associated with a longer incubation time, but also with a greater cull rate (percentage of lowquality chicks not kept for rearing). Chicks from small eggs are the quickest to hatch (Kumpula and Fasenko, 2005; Vieira et al., 2005).

Vieira et al. (2005) found that eggs of young breeders ( 27 weeks old) hatched earlier than those of old breeders (59 weeks old). This was in contrast with Almeida et al. (2008), who found that eggs of old and mid-age breeders hatched earlier. However, Reis et al. (1997) did not find differences in Hatch Time of eggs from young (32 to 34 weeks) or old (48 to 50 weeks) breeders. These discrepancies may be due to the use of different incubation methods (single stage $v s$ multistage) or different incubation settings (temperature, humidity or ventilation).

Mortality in chicks from older breeders (63 weeks) was higher (9.67\%) compared with $5.04 \%$ and $3.11 \%$ for young breeders of 35 weeks and 27 weeks respectively (Peebles et al., 1999a). Chicks from young breeders (35 weeks) had a better quality (98 vs 94 out of 100, with chick quality evaluated using a 100-point scale) compared with mid-age breeders (45 weeks); but the quality of chicks deteriorated in mid-age breeders when eggs were stored for 7 days (97 vs 79 out of 100) (Tona et al., 2004a). Eggs from different breeds may hatch differently too. It was demonstrated by Tonaet al. (2004b) that eggs of heavy breeds hatched earlier (1.3 to $1.6 \mathrm{~h}$ ) compared to those from dwarf gene breeds.

\section{Health status of breeders}

Desired levels of egg production, high internal and shell quality of hatching eggs, optimum hatchability and quality of chicks may not be achieved when there are health problems in the breeders. For instance, breeders infected with intestinal protozoa had reduced egg production (7.5\%) (Smit et al., 1998; Stephens and Hampson , 2002) and lower egg quality, resulting in an increased number of weak chicks with slower growth and poorer Feed Conversion Rates (FCR) than the progeny of unaffected flocks (Smit et al., 1998). A number of other infectious and non-infectious disorders are known to affect fertility, egg production, and possibly quality of chicks. Common sense dictates that comprehensive bio-security and health programs remain in practice at the breeder farm level. Any deficiencies at this stage will adversely affect production performance parameters (Roberts et al., 2011).

\section{Breeder feed}

Both the quantity and quality of breeder feed may affect the subsequent quality of the eggs and progeny. With regards to quantity, both feed excess and deprivation are detrimental. Underfeeding the hen can have an impact on chick quality, and this is particularly noticeable in the early production period. Low feed allocation in young commercial breeder flocks has been shown to compromise nutrient transfer to the egg, resulting in increased embryonic death-(which is not desirable at any stage), poorer chick viability and uniformity (Leeson, 2004). In breeders fed ad libitum (widely used as an overfeeding model), ovarian development is affected and results in excessive follicular development or 'Erratic Oviposition and Defective Egg Syndrome' (EaDES). Breeders with EaDES have poor egg shell quality, a reduced duration of fertility and 
poor hatchability. It was also reported that semen survival is lower, but it is not clear how semen was affected and if weaker embryos were generated (Leeson, 2004). With regard to quality, the composition of breeder feed affects egg weight and composition and as a consequence also affects hatchability and the quality of progeny, specifically body weight, immunity, and metabolism Peebles et al., 2002a; 2002b; 2007; Pappas et al., 2005; 2006a; 2006b). Indeed, the developing embryo and newly hatched chick are completely dependent for their growth and development on nutrients deposited in the egg.

\section{Storage duration and conditions}

The effect of storage time on hatchability was significant (Table 4). To achieve maximum hatchability, it is recommended that eggs be stored for no longer than three days, and temperature and relative humidity (RH) during egg storage should be maintained at $18^{\circ} \mathrm{C}$ and $70-78 \%$, respectively. Fertile eggs stored in the recommended conditions of temperature and humidity completely failed to hatch when held in storage for more than 25 day (Table 4). Even after seven days of storage (hatchability of 87 to $90 \%$ ), a significant (3to $76 \%$ ) reduction in hatchability was noticed (Butcher and Nilipour, 2009). When egg storage periods are prolonged, temperature and relative humidity $(\mathrm{RH})$ settings need to be adjusted to preserve internal integrity of eggs.

Generally, as egg storage time increases, temperature in the storage room should be decreased and $\mathrm{RH}$ increased to prevent dehydration (Christensen et al., 2002; Elibol et al., 2002a; 2002b). For instance, eggs can be stored at a temperature of 18 to $20^{\circ} \mathrm{C}$ for up to eight days. If storage is longer, temperature has to be dropped to 15 to $16^{\circ} \mathrm{C}$ (Kirk et al., 1980). Turning eggs seems to be more important for eggs from older breeders (Elibol et al., 2002a; $2002 b)$. However, it is recommended to avoid the exposure of eggs from old breeders to high temperature $\left(36^{\circ} \mathrm{C}\right)$ for extended periods before storage (Silva $e t$ al., 2008). Hatchability could be improved by allowing a longer incubation time $(0.7$ to $1.28 \mathrm{hr} \mathrm{day}^{-1}$ of storage (Table 1 ).

\section{Sexing embryos}

No differences in weight were observed between males and females during embryo development (Table 2). However, the sex of the embryo affected Hatch Time. Females hatched earlier than males, and the difference in peak hatching time between females and males was between 2.3 to $3.3 \mathrm{hr}$. This was in agreement with several other researchers (Reis et al., 1997). After $504 \mathrm{hr}$ of incubation, $71 \%$ of females were already hatched, compared to only 52 to $57 \%$ of the males (Burke, 1992). These results are in agreement with a study by Van de Ven $e t$ al. (2011) who found that $78 \%$ of the total hatched chicks after $465 \mathrm{hr}$ of incubation were females, while after $493 \mathrm{hr}$ only $42 \%$ of total hatched chicks were females.

\section{Effect of incubation conditions}

The factors which influence embryo temperature are heat production of the embryo itself (varying according to breed, breeder age, stage of incubation, and level of overheating), temperature in the setter and hatcher, air velocity (a higher air velocity induces more heat loss) and humidity as discussed farther under several headings in detail. 


\section{Temperature during incubation}

When the average storage temperature was increased from 13.6 to $20.6^{\circ} \mathrm{C}$, (Table 4), the Hatch Time decreased by $0.58 \mathrm{hr}$. This is attributed to increased metabolism of the embryo with optimal leading to quicker organ development and strength of the formed organs to facilitate easy hatching . This is in agreement with the findings by Jagdev (2011), who reported that the Hatch Time decreased by 0.50 hr.

Optimal incubation temperature for avian species varies from 33 to $39{ }^{\circ} \mathrm{C}$ (Visschedijk, 1991). In broilers, the highest hatchability, chick quality, and post-hatch performance (FCR and body weight) were obtained when eggs were incubated at an average temperature of $37.8{ }^{\circ} \mathrm{C}$. This optimal incubation temperature lies within the range of 37 to $38{ }^{\circ} \mathrm{C}$ (Decuypere et al., 2001; Hulet et al., 2007; Saito and Kita, 2011). Hatched chicks that experienced heat stress during incubation were weaker, less alert and had a higher incidence of culls. Indeed, exposure to temperatures of $46.1{ }^{\circ} \mathrm{C}$ for $3 \mathrm{hr}$ or $48.9^{\circ} \mathrm{C}$ for $1 \mathrm{hr}$ at day 16 of incubation may be lethal for embryos (Wilson, 1991). Hill (2002) reported that the metabolism of optimally incubated birds is able to direct resources to organ development and growth; whereas those incubated outside the optimal temperature must utilise resources to survive and, therefore, show reduced development and growth. In this research (Table 4), decreasing the hatch time, from 1.28 to $0.7 \mathrm{hr}$ was important because the shortened time allows for resource economisation like electricity required to run the incubators, reduces time for booking day-old -chicks in the case of a commercial hatchery, and gives to time for the hatchery manager to do other duties.

\section{Humidity during incubation}

There was significance difference $(\mathrm{P}<0.05)$ of humidity on hatchability (Table 5). When water in the dish below the hatch tray was full, there was no problem with hatching. However, when little water was put, there was massive failure of chicks to get out of their shells (79.2\%); leading to embryonic death from chicks which were fertile at candling (Table 5). This is referred to as 'sticky hatch'. Chicks tended to be smaller and more dehydrated when humidity during incubation was low with a high prevalence of unhealed navels (Crespo and Shivaprasad, (2003). However, no difference in chick body weight was observed in another study when eggs were incubated under different humidity levels (43, 53 and 63\%) (Bruzual et aI.,2000). Water tends to absorb excess heat from the incubator, hence, creating a balance in humidity that prevents dehydration of the chicks leading to easy hatching.

\section{Delay in feed and water intake post- hatch}

For chicks that were hatched with full water in hatch tray (Table 5), 398 eggs out of 405 eggs incubated (98.3\%) hatched live and were able to keep strong and alert even after 16 hours, without water or feed. For the chicks where the hatch tray was empty, 83 eggs out of 400 eggs $(20.8 \%)$ hatched live, and only remained strong and alert for $4.5 \mathrm{hr}$ before water and feed was given. This is because when the humidity is high, the metabolic processes in the chick are low and eggs do not lose water by dehydration or perspiration; therefore, after hatch chicks still have inherent metabolites to utilise to keep strong and alert for long. The chicks that were able to hatch in an empty tray (tray that did not have water) were weak at hatch due 
to dehydration and perspiration of the embryo before hatching. In this process, the chick depletes the inherent metabolites due to increased metabolism during embryonic stage. It is this depletion of metabolites that lessens the time for chicks to be strong and alert after hatch. Other researchers found that birds that hatch early may be held for several hours without food or water (The Poultry Site, 2008). Typically, the longer the hatched chicks remained in the hatcher, the worse their final performance (Fanguy et aI., 1980). Similarly, Wyatt et al. (1985) observed that chicks which remained in hatching trays between 14-32 hr weighed 5-32\% less than chicks maintained in trays for up to $7 \mathrm{hr}$.

Using male broiler chickens, Nir and Levanon (1993) found that growth retardation caused by 24 or $48 \mathrm{hr}$ holding periods was equivalent to a loss of one or two days body weight gain at market age, respectively. Hager and Beane (1983) and Baiao and Cancado (1998) carried out experiments to evaluate the effect of maintaining chicks in the hatching chambers. Birds were removed from the hatcher after incubation periods between 486 hand $522 \mathrm{hr}$. Hager and Beane (1983) observed significant negative effects on performance only in birds removed from the hatcher at $522 \mathrm{hr}$, but Baiao and Cancado (1998) did not observe any statistical differences in the performance of broilers. On the other hand, Casteel et al. (1994) found that the weight of chicks held for $24 \mathrm{hr}$ after hatching was less than those removed directly after hatch. Comparing the performance of birds fed immediately after hatching with the performance of birds fed $36 \mathrm{hr}$ later resulted in a 100-200 $\mathrm{g}$ lower body weight at 40 days of age. Feeding in the hatching trays not only limited this weight loss, but improved growth and uniformity of birds up to 21 days after placement (Sklan et aI., 2000).

\section{Acknowledgement}

The authors acknowledge the financial support from the World Bank, NARO Secretariat, and the research team.

\section{References}

Abiola, S.S., Meshioye, O.O., Oyerinde, B.O. and Bamgbose, M.A. 2008. Effect of egg size on hatchability of broiler chicks. Archivos de Zootecnia 57: 83-86.

Almeida, J.G., Vieira, S.L., Gallo, B.B., Conde, O.R.A. and Olmos, A.R. 2006. Period of incubation and post hatching holding time influence on broiler performance. Revista Brasileira de Ciencia Avicola 8: 153 - 158.

Almeida, J.G., Vieira, S.L., Reis, R.N., Berres, J., Barros, R., Ferreira, A.K. and Furtado, F.V.F. 2008. Hatching distribution and embryo mortality of eggs laid by broiler breeders of different ages. Revista Brasileira de Ciencia Avicola 10: 89-96.

Baiao, N.C. and Canc Ado, S.V. 1998. Effect of holding time between hatching and housing on broiler performance. Arquivo Brasileiro De Medicina Veterinaria E Zootecnia 50:191-194.

Barbosa, V.M., Canc;:Ado, S.V., Baiao, N.C., Lana, A.M.Q., Lara, L.J.C. And Souza, M.R. 2008. Effects of relative air humidity in the hatchery and breeder hen age on the incubation yield. Arquivo Brasileiro de Medicina Veterinaria e Zootecnia 60: 741-748. 
Bohren, B.B., Crittenden, L.B. and King, Rt. 1961. Hatching time and hatchability in the fowl. Poultry Science 40: 620-633.

Brake, J., Walsh, T., Benton Jr., C., Petltte, J., Meijerhof, R. and Penalva, G. 1997. Egg handling and storage. Poultry Science 76:144-151.

Bruzual, J., Peak, S., Brake, J. and Peebles, E. 2000. Effects of relative humidity during the last five days of incubation and brooding temperature on performance of broiler chicks from young broiler breeders. Poultry Science 79: 1385-1391.

Burke, W.H. 1992. Sex differences in incubation length and hatching weights of broiler chicks. Poultry Science 71: 1933-1938.

Burton, F.G. and Tullett, S.G. 1985. The effects of egg weight and shell porosity on the growth and water balance of the chicken embryo. Comparative Biochemistry and Physiology Part A: Physiology 81:377- 385.

Butcher, G.D. and Nilipour, A.H. 2009. Management of hatching eggs and broiler performance. In: Institute of Food and Agricultural Sciences Extension, http://edis.ifas.ufi.edu/ vm095. Accessed September 12 ${ }^{\text {th }}$, 2015.

Caregid, C., Tona, K., Onagbesan, 0., Buyse, J., Decuypere, E. and Bruggeman, V. 2005. The effects of the spread of hatch and interaction with delayed feed access after hatch on broiler performance until seven days of age. Poultry Science 84:13141320.

Crespo, R. and Sidvaprasad, H.L. 2003. Developmental, metabolic, and other noninfectious disorders, in: Saifa, Y.M. (Ed.) Diseases of poultry, pp. 10551102. Ames, Iowa State Press, USA.
Crittenden, L.B. and Bohren, B.B. 1961 The genetic and environmental effects of hatching time, egg weight and holding time on hatchability. Poultry Science 40:1736-1750.

Decuypere, E., Tona, K” Bruggeman, V. and Bamelis, F. 2001. The day-old chick: A crucial hinge between breeders and broilers. World's Poultry Science Journal 57: 127-138.

Elibol, O. and Brake, J. 2008b. Effect of egg weight and position relative to incubator fan on broiler hatchability and chick quality. Poultry Science 87: 1913-1918.

Elibol, O., Hodgetts, B. and Brake, J. 2002a. The effect of storage and prewarming periods on hatch time and hatchability. Poultry and Avian Biology Reviews 13:243-244.

Elibol, O., Peak, S. and Brake, J. 2002b. Effect of flock age, length of egg storage, and frequency of turning during storage on hatchability of broiler hatching eggs. Poultry Science 81: 945-950.

Fanguy, R.C., Misra, L.K. and Yo, K,V. 1980. Effect of delayed placement on growth performance of commercial broilers. Poultry Science 59:12151220.

French, N. 1997. Modeling incubation temperature: the effects of incubator design, embryonic development, and egg size. Poultry Science 76:124-133.

Gumulka, M. and Kapkowska, E. 2005. Age effect of broiler breeders on fertility and sperm penetration of the perivitelline layer of the ovum. Animal Reproduction Science 90:135-148.

Hager, J.E. and Beane, W.L. 1983. Post hatch incubation-time and early growth of broiler-chickens. Poultry Science 62: 247-254. 
Hagger, C., Steiger-Stafl, D. and Marguerat, C. 1986. Embryonic mortality in chicken eggs as influenced by egg weight and inbreeding. Poultry Science 65:812-814.

Hill, D. 2002. Chick length uniformity profiles as a field measurement of chick quality. International Hatchery Practice 16:

Hulet, R., Gladys, G., Hill, D., Meijerhof, R. and El-Shiekh, T. 2007. Influence of egg shell embryonic incubation temperature and broiler breeder flock age on post-hatch growth performance and carcass characteristics. Poultry Science 86:408-412.

Jagdev Sharma. 2011. A new breed: Highly productive chickens help raise Ugandans from poverty researcher at the Center for Infectious Diseases and Vaccinology at ASU's Biodesign Institute. https://asunews.asu.edu/ node $/ 21034$

Kirk, S., Emmans, G.C., Mcdonald, R. and Arnot, D. 1980. Factors affecting the hatchability of eggs from broiler breeders. British Poultry Science 21: 37-53.

Kumpula, B.L. and Fasenko, G.M. 2005. Comparing incubation duration, hatchability, and chick quality parameters of chicks from three egg sizes and two modem strains. Poultry and Avian Biology Reviews 16:57-58.

Leeson, S. 2004. Future challenges in poultry meat production. In: Tucker, L.A. and Taylor-Pickard, 1.A. (Eds.) Interfacing immunity, gut health and performance (Nottingham, UK, Nottingham University Press). pp. 17.

Moran, E.T. 1990. Effects of egg weight, glucose-administration at hatch, and delayed access to feed and water on the poultry at 2 weeks of age. Poultry Science 69:1718-1723.

Nir, I. and Levanon, M. 1993. Effect of post hatch holding time performance and residual yolk and liver composition. Poultry Science 72:1994-1997.

Pappas, A., Acamovic, T., Sparks, N., Sural, P. and Mcdevitt, R. 2005. Effects of supplementing broiler breeder diets with organic selenium and polyunsaturated fatty acids on egg quality during storage. Poultry Science 84: 865-874.

Peebles, E., Doyle, S., Pansky, T., Gerard, P., Latour, M., Boyle, E. and Smith, T. 1999a. Effects of breeder age and dietary fat on subsequent broiler performance. 1 . Growth, mortality, and feed conversion. Poultry Science 78: 505-511.

Peebles, E., Zumwalt, E., Gerard, P., Latour, M. and Smith, T. 2002a. Market age live weight, carcass yield, and liver characteristics of broiler offspring from breeder hens fed diets differing in fat and energy contents. Poultry Science 81:23-29.

Raju, M., Chawak, M.M., Praharaj, N.K., Rao, S.V.R. and Mishra, S.K. 1997. Interrelationships among egg weight, hatchability, chick weight, post-hatch performance and rearing method in broiler breeders. Indian Journal of Animal Sciences 67:48-50.

Reis, L.H., Gama, L.T. and Soares, M.C. 1997. Effects of short storage conditions and broiler breeder age on hatchability, hatching time, and chick weights. Poultry Science 76:14591466.

Roberts, J.R., Souillard, R. and Bertin, J. 2011. Avian deseases which affect egg production and quality. In: Nys, Y., Bain, M. and Van Immerseel, F. (Eds.). 
Improving the safety and quality of eggs and agg products. Volume 1: Egg chemistry, production and composition, (Cambridge, Woodhead Publishing Limited). pp. 376-393.

Rosa, P.S., Guidoni, A.L., Lima, I.L. and Bersch, F.X.R. 2002. Effect of incubation temperature on hatching results of broiler breeders eggs classified by weight and hen age. RevistaBrasileira de Zootecnia 31: 1011-1016.

Saito, F. and Kita, K. 2011. Maternal intake of Astaxanthin improved hatchability of fertilized eggs stored at high temperature. Journal of Poultry Science 48:33-39.

Shivazad, M., Bejaei, M., Taherkhani, R., Zaghari, M. and Kiaei, M.M. 2007. Effects of glucose injection and feeding oasis on broiler chick's subsequent performance. Pakistan Journal of Biological Sciences 10:1860-1864.

Sklan, D. and Noy, Y. 2000. Hydrolysis and absorption in the small intestines of post hatch chicks. Poultry Science 79:1306-1310.

Smit, H.F., Dwars, R.M., Davelaar, F.G. and Wljtten, G.A.W. 1998. Observations on the influence of intestinal spirochaetosis in broiler breeders on the performance of their progeny and on egg production. Avian Pathology 27:133-141.

Stephens, C.P. and Hampson, D.J. 2002. Experimental infection of broiler breeder hens with the intestinal spirochaete Brachyspira (Serpulina) pilosicoli causes reduced egg production. Avian Pathology 31:169175.

Tanure, C., Cafe, M.B., Leandro, N.S.M., Balao, N.C., Stringhini, J.H. and Gomes, N.A. 2009. Effects of ages of light breeder hens and storage period of hatchable eggs on the incubation efficiency. Arquivo Brasileiro de Medicina Veterinaria e Zootecnia 61: 1391-1396.

Tona, K., Bamelis, F., Coucke, W., Bruggeman, V. and Decuypere, E. 2001. Relationship between broiler breeder's age and egg weight loss and embryonic mortality during incubation in large-scale conditions. Journal of Applied Poultry Research 10: 221227.

Tona, K., Bamelis, F., De Ketelaere, B., Bruggeman, V., Moraes, V., Buyse, J., Onagbesan, O. And Decuypere, E. 2003. Effects of egg storage time on spread of hatch, chick quality, and chick juvenile growth. Poultry Science 82: 736-741.

Tona, K., Onagbesan, O., De Ketelaere, B., Decuypere, E. and Bruggeman, V. 2004a. Effects of age of broiler breeders and egg storage on egg quality, hatchability, chick quality, chick weight, and chick post hatch growth to forty-two days. Journal of Applied Poultry Research 13:10-18.

Tona, K., Onagbesan, O.M., Jego, Y., Kamers, B., Decuypere, E. and Bruggeman, V. 2004b. Comparison of embryo physiological parameters during incubation, chick quality, and growth performance of three lines of broiler breeders differing in genetic composition and growth rate. Poultry Science 83:507-513.

Tong, Q., Mcgonnell, I.M., Romanini, C.E.B., Exadaktylos, V., Berckmans, D., Bergoug, H., Guinebretiere, M., Eterradossi, N.R., N., Garain, P. and Demmers, T. 2011. Monitoring environmental conditions during incubation of chicken eggs. $15^{\prime} \mathrm{h}$ 
International Congress on Animal Hygiene, Vienna, Austria., pp. 117119.

Van De Ven, L.J.F., Van Wagenberg, A.V., De Bonne, M., Decuypere, E., Kemp, B. and Van Den Brand, H. 2011. Hatching system and time effects on broiler physiology and post-hatch growth. Poultry Science 90:12671275.

Victoria Sandilands; Paul M. Hocking $1^{\text {st }}$ January 2012. Alternative systems for poultry: Health, welfare and productivity, CABI, p. 119 , ISBN 9781-78064-009-9

Vieira, F.M.C., Silva, I.J.O., Barbosa Filho, J.A.D., Vieira, A.M.C. and Broom, D.M. 2010. Preslaughter mortality of broilers in relation to lairage and season in a subtropical climate.Poultry Science 90:21272133.

Vieira, S., Almeida, J., Lima, A., Conde, O. and Olmos, A. 2005. Hatching distribution of eggs varying in weight and breeder age. Revista Brasileira de Ciencia Avicola 7:73-78.

Vieira, S.L. and Moran, E.T. 1999. Effects of egg of origin and chick post-hatch nutrition on broiler live performance and meat yields. World's Poultry Science Journal 55:125-142.

Visschedijk, A.H.J. 1991. Physics and physiology of incubation. British Poultry Science 32:3-20.

Wilson, H.R. 1991. Interrelationships of egg size, chick size, posthatching growth and hatchability.World's Poultry Science Journal 47:5-20.

Wolanski, N.J., Renema, R.A., Robinson, F.E., Carney, V.L. and Fancher, B.1. 2007. Relationships among egg characteristics, chick measurements, and early growth traits in ten broiler breeder strains. Poultry Science 86: 1784-1792.

Wyatt, C.L., Weaver, W.D. and Beane, W.L. 1985. Influence of egg size, egg shell quality, and post-hatch holding time on broiler performance. Poultry Science 64:2049-2055. 